\title{
Production-related contaminants (pesticides, antibiotics and hormones) in organic and conventionally produced milk samples sold in the USA
}

\author{
Jean A Welsh ${ }^{1,2, *}$, Hayley Braun ${ }^{1}$, Nicole Brown ${ }^{3}$, Caroline Um ${ }^{4}$, Karen Ehret ${ }^{5}$, \\ Janet Figueroa ${ }^{1}$ and Dana Boyd Barr ${ }^{5}$ \\ 'Department of Pediatrics, Emory University School of Medicine, W-450 Health Sciences Research Building - Room \\ E400, 1760 Haygood Drive NE, Atlanta, GA 30322, USA: 'Wellness Department, Children's Healthcare of Atlanta, \\ Atlanta, GA, USA: ${ }^{3}$ Department of Pharmacology, Emory University School of Medicine, Atlanta, GA, USA: \\ ${ }^{4}$ Department of Epidemiology, Rollins School of Public Health, Atlanta, GA, USA: ${ }^{5}$ Department of Environmental \\ Health, Rollins School of Public Health, Atlanta, GA, USA
}

Submitted 20 January 2018: Final revision received 26 February 2019: Accepted 27 February 2019; First published online 26 June 2019

\begin{abstract}
Objective: Consumption of cow's milk, which is associated with diet and health benefits, has decreased in the USA. The simultaneous increase in demand for more costly organic milk suggests consumer concern about exposure to productionrelated contaminants may be contributing to this decline. We sought to determine if contaminant levels differ by the production method used.

Design: Half-gallon containers of organic and conventional milk (four each) were collected by volunteers in each of nine US regions and shipped on ice for analysis. Pesticide, antibiotic and hormone (bovine growth hormone (bGH), bGHassociated insulin-like growth factor 1 (IGF-1)) residues were measured using liquid or gas chromatography coupled to mass or tandem mass spectrometry. Levels were compared against established federal limits and by production method.

Setting: Laboratory analysis of retail milk samples.

Results: Current-use pesticides ( $5 / 15$ tested) and antibiotics ( $5 / 13$ tested) were detected in several conventional (26-60\%; $n$ 35) but not in organic ( $n$ 34) samples. Among the conventional samples, residue levels exceeded federal limits for amoxicillin in one sample (3\%) and in multiple samples for sulfamethazine (37\%) and sulfathiazole (26\%). Median bGH and IGF-1 concentrations in conventional milk were 9.8 and $3.5 \mathrm{ng} / \mathrm{ml}$, respectively, twenty and three times that in organic samples $(P<0.0001)$. Conclusions: Current-use antibiotics and pesticides were undetectable in organic but prevalent in conventionally produced milk samples, with multiple samples exceeding federal limits. Higher bGH and IGF-1 levels in conventional milk suggest the presence of synthetic growth hormone. Further research is needed to understand the impact of these differences, if any, on consumers.
\end{abstract}

Keywords
Milk
Organic
Production
Contaminants
Pesticides
Antibiotics
Hormones
Insulin-like growth factor 1

Milk consumption is associated with better diet quality and improved health ${ }^{(1-5)}$. Despite dietary guidance encouraging its consumption ${ }^{(6)}$, milk intake has been decreasing in the $\mathrm{USA}^{(7)}$. At the same time, the demand for milk produced organically has increased ${ }^{(8)}$. These trends suggest that concern about exposure to production-related chemicals including pesticides, antibiotics and growth hormones is playing a role in the decline of conventional milk intake ${ }^{(8,9)}$.

Pesticides are widely used in US food production to control pests, weeds, etc. in crops and to protect cattle from insects ${ }^{(10)}$. Research suggests that with sufficient exposure, some pesticides may lower birth weight, contribute to delayed motor and neurological development ${ }^{(11)}$, and increase cancer risk ${ }^{(12)}$. The maximum residue limit or tolerance limit in food is the amount of pesticide residue allowed to remain in or on a food ${ }^{(13)}$. These limits, based on the toxicity, frequency, amount of application and potential routes of exposure, have been developed by the US Environmental Protection Agency ${ }^{(14)}$. While these limits take into consideration the dietary differences and needs between adults and children, information about 
pesticide exposure and its related risks is very limited. Little is known about the real-life, often prolonged exposure to combinations of pesticides that may compound any effect ${ }^{(15,16)}$. Also unknown is the extent to which consumers are exposed to pesticides in milk and whether exposure differs when the milk consumed is produced using organic $v$. conventional methods. Luzardo et al. tested samples of milk sold in Spain and found low levels of the persistent pesticides organochlorines and polychlorobiphenyls in both organic and conventionally produced samples ${ }^{(17)}$, but no similar studies have been done to assess exposure to pesticides, either persistent or current-use pesticides, in milk produced in the USA.

Antibiotics are also commonly used in food production $^{(9)}$. They are used prophylactically as well as to treat infections. They are also used to promote growth in animals raised for food ${ }^{(9,18)}$. The presence of antibiotics in the food supply has raised concerns about their possible role in increasing antibiotic resistance and hypersensitivity reactions ${ }^{(9,19,20)}$. Tolerance levels for antibiotics used in food production have been established by the US Food and Drug Administration (FDA) ${ }^{(21,22)}$. A drug, or its metabolites, is considered safe at levels believed to have little risk of toxicity or if it has been determined to be biologically inactive ${ }^{(22)}$. To help limit exposure to drug residues in milk, every tanker-truck entering a dairy processing plant is tested, although that testing is done only for only a small proportion of the antibiotics being used ${ }^{(22-24)}$. Only one known study, done a decade ago, has compared antibiotic residues in organic $v$. conventionally produced milk $^{(24)}$.

Bovine growth hormone (bGH), also known as bovine somatotropin, is a protein produced normally by the pituitary gland of cows and other mammals that regulates the production of milk $^{(25)}$. In 1993, the FDA approved the use of synthetic or recombinant bovine growth hormone (rbGH) by the dairy industry but concerns regarding its safety persist ${ }^{(26)}$. These concerns include the possible impact of rbGH's stimulation of insulin-like growth factor 1 (IGF-1) production in man and evidence suggesting that dairy cows treated with rbGH have more frequent infections ${ }^{(26,27)}$. More treatment of infections increases the exposure to antibiotics, and raises the risk of antibiotic resistance, among milk consumers ${ }^{(28)}$. While the evidence is mixed, studies have associated higher IGF-1 levels in man with increased risk of cancer ${ }^{(29-32)}$ and have raised concerns about a possible influence on immune response $^{(33)}$ and in the growth and development in children ${ }^{(34-36)}$. Previous studies have concluded that, because growth hormone is species-specific and it is degraded in digestion, it is unlikely to have a biological impact on milk consumers $^{(37)}$. More recent evidence of increased growth hormone-related antibodies in the circulation of rodents given bGH orally has cast some doubt on that conclusion ${ }^{(28,35)}$.

Given the prominent role of milk in the US diet, particularly in the diets of children ${ }^{(38)}$ and those whose consumption continues into adulthood ${ }^{(39)}$, the present study was done to assess the extent to which pesticides, antibiotics and synthetic hormones are present in retail milk and to determine how levels compare when produced using organic $v$. conventional methods.

\section{Methods}

\section{Sample collection}

Milk samples were collected in August 2015 from each of nine regions dividing the continental USA. Regional boundaries were those specified on a map made publicly

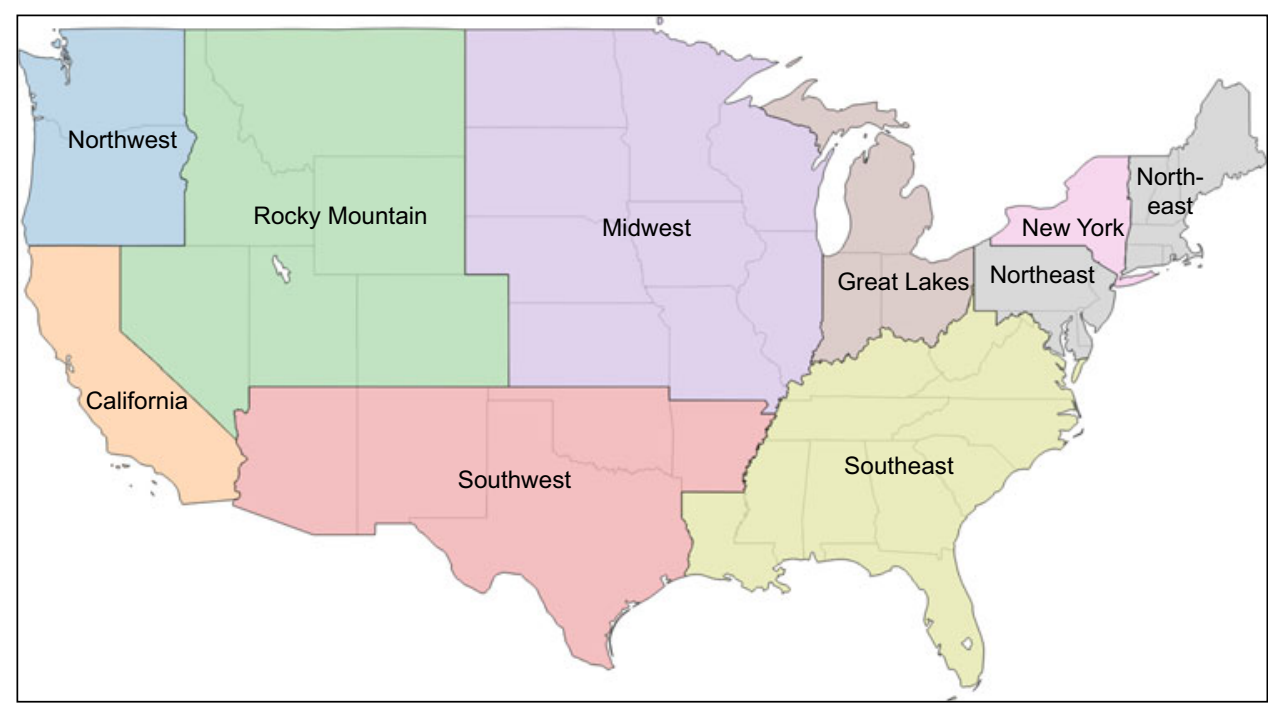

Fig. 1 (colour online) Map indicating the boundaries of each of the nine continental US regions from which a set of milk samples (three different brands of organically produced $2 \%$ milk, three different brands of conventionally produced $2 \%$ milk, and one each of organic and conventional whole milk) were collected in August 2015 
Table 1 Origin of milk samples available for analysis

\begin{tabular}{|c|c|c|c|c|c|c|}
\hline \multirow[b]{2}{*}{ Region } & \multirow[b]{2}{*}{ City } & \multicolumn{2}{|c|}{$\begin{array}{c}\text { Number of } 2 \% \text { milk } \\
\text { samples }\end{array}$} & \multicolumn{2}{|c|}{$\begin{array}{l}\text { Number of whole milk } \\
\text { samples }\end{array}$} & \multirow[b]{2}{*}{ Total } \\
\hline & & Organic & Conventional & Organic & Conventional & \\
\hline California & Oceanside, CA & 3 & 3 & 1 & 1 & 8 \\
\hline Great Lakes & Grand Rapids, MI & 3 & 3 & 1 & 1 & 8 \\
\hline Midwest & Davenport, IA & 3 & 3 & 1 & 1 & 8 \\
\hline New England & West Orange, NJ & 3 & 3 & 1 & 1 & 8 \\
\hline New York & Brooklyn, NY & 3 & 2 & 1 & 1 & 7 \\
\hline Northwest & The Dalles, OR & 3 & 3 & 1 & 1 & 8 \\
\hline Rocky Mountain & St. George, UT & 1 & 3 & 1 & 1 & 6 \\
\hline Southeast & Atlanta, $\mathrm{GA}$ & 3 & 3 & 1 & 1 & 8 \\
\hline Southwest & Buckeye, AZ & 3 & 3 & 1 & 1 & 8 \\
\hline Total & & 25 & 26 & 9 & 9 & 69 \\
\hline
\end{tabular}

available by one milk distributor with sales nationally (see Fig. 1) ${ }^{(40)}$. The selection of the specific collection site within each region was based on the location of the first volunteer shopper identified by the research team (with the assistance of friends, family and co-workers) who agreed to procure the samples and ensure that they were properly shipped to the laboratory. In each region (Table 1), eight half-gallon (1.89 litre) milk cartons were obtained from one or more retail stores selected by the volunteer for their convenience. This included six cartons of $2 \%$ milk, the type most commonly consumed by US children ${ }^{(7)}$, three of which were labelled as different US Department of Agriculture-certified organic brands and three labelled as different conventional brands. In addition, given the known lipophilic nature of some pesticides, two samples of whole milk, one US Department of Agriculture-certified organic and one conventional, were obtained. Flavored and other specialty milks were excluded. All samples were shipped overnight in their original sealed containers in a single cooler and delivered on ice to Rollins School of Public Health at Emory University in Atlanta, GA. Samples were processed and labelled using a studygenerated identification number to ensure blinding during laboratory analysis and stored at $-20^{\circ} \mathrm{C}$ until analysis.

\section{Laboratory analysis}

Milk samples were spiked with isotopically labelled internal standards, when available, subjected to liquid-liquid or solid-phase extraction, and pre-concentrated. Samples were tested for the residues of commonly used pesticides and antibiotics, as determined in consultation with dairy industry experts, using previously validated methods ${ }^{(41)}$. Pesticide analysis was conducted via GC-MS/MS with stable isotope $\left({ }^{13} \mathrm{C}\right)$ dilution quantification. Isotopically labelled internal standards were obtained from Cambridge Isotope Laboratories (Tewksbury, MA, USA) and unlabelled standards were obtained from Sigma Aldrich (St. Louis, MO, USA). The limit of detection (LOD) for each analyte varied but was in the low $\mathrm{pg} / \mathrm{ml}$, ranging from 0.02 $\mathrm{pg} / \mathrm{ml}$ for atrazine to $20 \mathrm{pg} / \mathrm{ml}$ for chlorpyrifos and cypermethrin (Table 3). Analysis for antibiotic residues was performed via HPLC-high-resolution linear ion trap (LTQ Orbitrap; Thermo Scientific, San Jose, CA, USA) where the LTQ accumulates, isolates and fragments ions for MS/MS confirmation. Isotopically labelled internal standards were not available so external calibration was performed for quantification. Standards were purchased from Sigma-Aldrich. The LOD for antibiotics was $1 \mathrm{ng} / \mathrm{ml}$ (Table 3). Hormones were measured using a slight modification of the method of Kay et al. ${ }^{(42)}$ to allow for milk analysis using ultraperformance liquid chromatographyhigh-resolution MS using a Velos LTQ Orbitrap (Thermo Scientific). The LOD for bGH and IGF-1 were 0.40 and $0 \cdot 10 \mathrm{ng} / \mathrm{ml}$, respectively. Similar to antibiotics, external calibration without stable isotopes was used for quantification. All studies included a concurrent analysis of positive and negative controls (10\%) to ensure method validity. Positive controls consisted of pooled organic cow's milk that was spiked with the target compounds at a concentration that was $10 \times$ the method LOD. These milk samples also contained residual levels of the target chemicals and so could not be used alone for method blanks. Negative controls included a simulated milk matrix consisting of water with $6 \%(\mathrm{v} / \mathrm{v})$ of vegetable oil and a pooled milk sample with the lowest possible analyte concentrations. Soya-based formulas were tested for blank materials but they did not appropriately mimic the recovery of the analytes from the milk as did the oil:water solution. In addition, all hormone analyses were performed in duplicate to ensure data accuracy.

\section{Statistical analysis}

The proportions of milk samples with detectable levels of each of the pesticides and antibiotics were calculated and Fisher's exact test of proportions was used to compare them by milk type (organic $v$. conventional). The levels in each sample were also compared with existing federal tolerance limits ${ }^{(14,21)}$. Due to deviations from a normal distribution, median levels of all chemicals of interest were reported for each milk type. Samples with values below the LOD were imputed as one-half the LOD of the laboratory method used for each chemical ${ }^{(43)}$. 
Table 2 Percentage of samples with detectable levels of pesticide and antibiotic residues by production method (conventional $v$. organic) in the set of retail milk samples collected in nine continental US regions, August 2015

\begin{tabular}{|c|c|c|c|c|c|}
\hline & \multicolumn{2}{|c|}{ Conventional ( $n$ 35) } & \multicolumn{2}{|c|}{ Organic (n 34) } & \multirow[b]{2}{*}{$P$ value } \\
\hline & $n$ detected & $\%$ & $n$ detected & $\%$ & \\
\hline \multicolumn{6}{|l|}{ Pesticides* } \\
\hline Hexachlorobenzene & 35 & 100 & 34 & 100 & - \\
\hline ppDDE & 35 & 100 & 34 & 100 & - \\
\hline ppDDT & 32 & 91 & 32 & 94 & 1.00 \\
\hline Atrazine & 9 & 26 & & & 0.002 \\
\hline Diazinon & 21 & 60 & & & $<0.0001$ \\
\hline Chlorpyrifos & 20 & 59 & & & $<0.0001$ \\
\hline Cypermethrin & 17 & 49 & & & $<0.0001$ \\
\hline Permethrin & 16 & 46 & & & $<0.0001$ \\
\hline Dicofol & \multicolumn{2}{|c|}{0} & \multicolumn{2}{|c|}{0} & - \\
\hline Endosulfan- $\alpha$ & \multicolumn{2}{|c|}{0} & \multicolumn{2}{|c|}{0} & - \\
\hline Chlorthalonil & \multicolumn{2}{|c|}{0} & \multicolumn{2}{|c|}{0} & - \\
\hline Fonofos & \multicolumn{2}{|c|}{0} & \multicolumn{2}{|c|}{0} & - \\
\hline Cyfluthrin & \multicolumn{2}{|c|}{0} & \multicolumn{2}{|c|}{0} & - \\
\hline Fenvalerat & \multicolumn{2}{|c|}{0} & \multicolumn{2}{|c|}{0} & - \\
\hline \multicolumn{6}{|l|}{ Antibiotics } \\
\hline \multicolumn{6}{|l|}{ Penicillins } \\
\hline Carbenicillin & \multicolumn{2}{|c|}{0} & \multicolumn{2}{|c|}{0} & - \\
\hline Amoxicillin & 15 & 43 & \multicolumn{2}{|c|}{0} & $<0.0001$ \\
\hline \multicolumn{6}{|l|}{ Tetracyclines } \\
\hline Oxytetracycline & \multicolumn{2}{|l|}{21} & \multicolumn{2}{|c|}{0} & $<0.0001$ \\
\hline \multicolumn{6}{|l|}{ Sulfonamides } \\
\hline Sulfamethazine & 13 & 37 & \multicolumn{2}{|c|}{0} & 0.0001 \\
\hline Sulfabromethazine & \multicolumn{2}{|c|}{0} & \multicolumn{2}{|c|}{0} & - \\
\hline Sulfadimethoxine & 18 & 51 & & & $<0.0001$ \\
\hline Sulfapyridine & \multicolumn{2}{|c|}{0} & & & - \\
\hline Sulfathiazole & 9 & 26 & & & 0.002 \\
\hline Ionophores & & & & & \\
\hline Monensin & & & & & - \\
\hline Lasalocid & & & & & - \\
\hline Pyrimidine inhibitor & & & & & \\
\hline Trimethoprim & & & & & - \\
\hline
\end{tabular}

${ }^{*} P$ value for conventional $v$. organic: Fisher's exact test of proportions $(P<0.05$ considered statistically significant).

Comparisons between median values of organic $v$. conventional milk were done using Wilcoxon rank-sum tests. To facilitate comparison with an earlier study ${ }^{(24)}$, the analysis for antibiotic and growth hormones was repeated to obtain adjusted least-squares means controlling for percentage of milk fat and region using generalized linear models. All statistical analyses were performed using the statistical software package SAS version 9.4 and a two-sided $P<0.05$ was considered statistically significant.

\section{Results}

A total of sixty-nine samples were collected (thirty-four organic and thirty-five conventional). Eight samples from seven of the nine study regions were available for analysis. This included three different brands of organic $2 \%$ milk, three different brands of conventional $2 \%$ milk, and one brand each of organic and conventional whole milk. From one region (New York) only two of the three requested samples of $2 \%$ conventional milk were available for analysis and from another (Rocky Mountain) only one of the three requested samples of $2 \%$ organic milk were available. A total of ten different brands of organic (with the number of samples per brand ranging from one to eleven) and eighteen different brands of conventional milk (with the number of samples per brand ranging from one to six) were collected. Of the ten different organic brands tested, four were purchased in multiple regions, including two brands that were purchased in three different regions, one in eight and one in all nine regions. Fewer of the eighteen conventional brands were purchased in more than one region, including one brand purchased in two regions and two brands purchased in three different regions.

\section{Pesticide results}

Residues of several currently used pesticides, including atrazine, chlorpyrifos, cypermethrin, diazinon, hexachlorobenzene and permethrin, were detected in many of the conventional milk samples (26-60\%) but in none of the organic samples (Table 2). Pesticide levels in the conventional samples were below the FDA limit for all with established limits (Table 3). All samples (conventional and organic) were free of detectable levels of the pesticides dicofol, endosulfan- $\alpha$, chlorthalonil, fonofos, cyfluthrin 
Table 3 Medians and ranges for pesticide and antibiotic residues by production method (conventional $v$. organic) in the set of retail milk samples collected in nine continental US regions, August 2015

\begin{tabular}{|c|c|c|c|c|c|c|}
\hline & \multirow[b]{2}{*}{ EPA limit for milk (pg/ml) } & \multicolumn{2}{|c|}{ Conventional ( $n$ 35) } & \multicolumn{2}{|c|}{ Organic (n 34) } & \multirow[b]{2}{*}{$P$ value* } \\
\hline & & Median (pg/ml) & Range (pg/ml) & Median (pg/ml) & Range (pg/ml) & \\
\hline \multicolumn{7}{|l|}{ Pesticides } \\
\hline Atrazinet & 20000 & $<0.01$ & $<0.01-0.29$ & \multicolumn{2}{|c|}{$<0.01$} & 0.0018 \\
\hline Hexachlorobenzene & NA & 236 & $49 \cdot 0-553$ & 45.5 & $23 \cdot 0-225$ & $<0.0001$ \\
\hline ppDDE & NA & 465 & $206-694$ & 303 & $110-492$ & $<0.0001$ \\
\hline ppDDT & NA & 51.6 & $<5-137$ & 45 & $<5-131$ & 0.38 \\
\hline Diazinon† & NA & $29 \cdot 0$ & $<5-150$ & \multicolumn{2}{|c|}{$<5$} & $<0.0001$ \\
\hline Chlorpyrifos† & 10000 & 112 & $<20-319$ & \multicolumn{2}{|c|}{$<20$} & $<0.0001$ \\
\hline Cypermethrint & 100000 & $<20$ & $<20-210$ & \multicolumn{2}{|c|}{$<20$} & $<0.0001$ \\
\hline Permethrint & 880000 & $<5$ & $<5-184$ & \multicolumn{2}{|c|}{$<5$} & $<0.0001$ \\
\hline Dicofol & - & \multicolumn{2}{|c|}{$<5$} & \multicolumn{2}{|c|}{$<5$} & - \\
\hline Endosulfan- $\alpha$ & - & \multicolumn{2}{|c|}{$<5$} & \multicolumn{2}{|c|}{$<5$} & - \\
\hline Chlorthalonil & - & \multicolumn{2}{|c|}{$<5$} & \multicolumn{2}{|c|}{$<5$} & - \\
\hline Fonofos & - & \multirow{2}{*}{\multicolumn{2}{|c|}{$\begin{array}{l}<5 \\
<5\end{array}$}} & \multicolumn{2}{|c|}{$<5$} & - \\
\hline Cyfluthrin & - & & & & & - \\
\hline \multirow[t]{2}{*}{ Fenvalerate } & - & \multicolumn{2}{|c|}{$<5$} & \multicolumn{2}{|c|}{$<5$} & - \\
\hline & FDA limit (ng/ml) & Median (ng/ml) & Range (ng/ml) & Median (ng/ml) & Range (ng/ml) & \\
\hline \multicolumn{7}{|l|}{ Antibiotics } \\
\hline \multicolumn{7}{|l|}{ Penicillins } \\
\hline Carbenicillin & - & \multicolumn{2}{|c|}{$<1$} & \multicolumn{2}{|c|}{$<1$} & - \\
\hline Amoxicillin† & 10 & $<1$ & $<1-10.2$ & \multirow{2}{*}{\multicolumn{2}{|c|}{$<1$}} & $<0.0001$ \\
\hline Tetracyclines & & & & & & \\
\hline Oxytetracycline† & 300 & $14 \cdot 6$ & $<5-147 \cdot 2$ & \multirow{2}{*}{\multicolumn{2}{|c|}{$<5$}} & $<0.0001$ \\
\hline Sulfonamides & & & & & & \\
\hline Sulfamethazine† & 0 & $<1$ & $<1-6 \cdot 8$ & & & $<0.0001$ \\
\hline Sulfabromethazine & 10 & & 1 & & & - \\
\hline Sulfadimethoxine† & 10 & $1 \cdot 2$ & $<1-7 \cdot 2$ & & & $<0.0001$ \\
\hline Sulfapyridine & 0 & & $\begin{array}{lll}-1 & 12 \\
\end{array}$ & & & - \\
\hline Sulfathioazole† & 0 & $<1$ & $<1-6 \cdot 0$ & & & 0.002 \\
\hline lonophores & & & & & & \\
\hline Monensin & - & & 10 & & & - \\
\hline Lasalocid & - & & 10 & & & - \\
\hline Pyrimidine inhibitor & & & & & & \\
\hline Trimethoprim & - & & 1 & & & - \\
\hline
\end{tabular}

EPA, US Environmental Protection Agency; NA, not applicable; FDA, US Food and Drug Adminisitration; LOD, limit of detection.

Samples with values $\angle L O D$ are indicated with ' $\angle Y$ ' where $Y$ is equal to the limit of detection for that chemical. Estimated values for samples $\angle L O D$ were imputed at $1 / 2 \times L O D$ for purposes of testing the differences between groups.

Results presented in bold indicate those antibiotics and pesticides for which the residue levels in at least one milk sample exceeded federal limits.

${ }^{*} P$ value for conventional $v$. organic: Wilcoxon rank-sum test $(P<0.05$ considered statistically significant). Wilcoxon-rank sum tests for differences in population mean ranks (distributions) and is not a median test (note significantly different samples with the same median values).

†Percentage of the total sample below the LOD is $>50 \%$; refer to Table 2 for comparisons of conventional $v$. organic samples using proportions detected instead (recommended by Helsel $\left.{ }^{(43)}\right)$.

and fenvalerate. Legacy pesticides, those now prohibited but that remain environmentally persistent ${ }^{(44)}$, hexachlorobenzene and ppDDT, and the DDT metabolite/degradant, ppDDE, were detected in nearly all of the organic as well as the conventional samples (91-100\%; Table 2). ppDDT was the only pesticide to have a median level that was not statistically significantly higher in conventional compared with organic samples $(P=0 \cdot 38)$.

\section{Antibiotic results}

The numbers of organic and conventional milk samples with detectable levels of antibiotic residues are presented in Table 2. While residues of at least one antibiotic were found in most of the conventional milk samples (60\%), none were detected in any of the organic samples. The median and range for all antibiotics tested are reported in Table 3. Estimated median levels of amoxicillin, oxytetracycline, sulfamethazine, sulfadimethoxine and sulfathiazole were all statistically significantly higher in conventional compared with organic milk $(P<0.0001$ to $P=0.0018)$. One of the thirty-five conventional samples $(3 \%)$ had an amoxicillin residue level of $10 \cdot 2 \mathrm{ng} / \mathrm{ml}$, exceeding the FDA limit of $10 \cdot 0 \mathrm{ng} / \mathrm{ml}^{(21)}$. In addition, residues of two sulfonamides with a zero tolerance level for use in lactating cattle, sulfamethazine and sulfathiazole, were detected in $37 \%$ and $26 \%$ of the conventional milk samples, respectively.

\section{Hormone results}

Levels of bGH and IGF-1 by milk production method are presented in Table 4. Median levels in conventional milk samples were $9.8 \mathrm{ng} / \mathrm{ml}$ for bGH and $3.5 \mathrm{ng} / \mathrm{ml}$ for IGF-1, approximately twenty and three times higher $(P<0.0001)$, respectively, than the $0.5 \mathrm{ng} / \mathrm{ml}$ and the $1 \cdot 1 \mathrm{ng} / \mathrm{ml}$ in the organic samples. Results of the sensitivity analysis adjusting for percentage of milk fat and region 
Table 4 Medians and ranges for hormone levels by production method (conventional $v$. organic) in the set of retail milk samples collected in nine continental US regions, August 2015

\begin{tabular}{|c|c|c|c|c|c|c|}
\hline \multirow[b]{2}{*}{ Hormones } & \multirow[b]{2}{*}{ FDA limit } & \multicolumn{2}{|c|}{ Conventional ( $n$ 35) } & \multicolumn{2}{|c|}{ Organic (n 34) } & \multirow[b]{2}{*}{$P$ value } \\
\hline & & Median (ng/ml) & Range (ng/ml) & Median (ng/ml) & Range (ng/ml) & \\
\hline $\begin{array}{l}\text { bGH } \\
\text { IGF-1 }\end{array}$ & $\begin{array}{l}\text { NA } \\
\text { NA }\end{array}$ & $\begin{array}{l}9.8 \\
3.5\end{array}$ & $\begin{array}{l}0.6-17 \cdot 0 \\
0.3-8 \cdot 1\end{array}$ & $\begin{array}{l}0.5 \\
1.1\end{array}$ & $\begin{array}{l}<0.4-4.6 \\
<0.1-3.8\end{array}$ & $\begin{array}{l}<0.0001 \\
<0.0001\end{array}$ \\
\hline
\end{tabular}

FDA, US Food and Drug Adminisitration; bGH, bovine growth hormone; IGF-1; insulin-like growth factor 1; NA, not applicable; LOD, limit of detection.

Estimated values for samples $<$ LOD were imputed at $1 / 2 \times L O D$ for purposes of testing the differences between groups.

${ }^{*} P$ value for conventional $v$. organic: Wilcoxon rank-sum test $(P<0.05$ considered statistically significant).

were similar to those obtained in the primary analysis. The adjusted least-squares mean $(95 \% \mathrm{CI})$ for bGH was $9.4(8.2,10 \cdot 7) \mathrm{ng} / \mathrm{ml}$ and for IGF-1 it was $3.9(3 \cdot 1,4.6)$ $\mathrm{ng} / \mathrm{ml}$ and both still differed significantly from their organic counterparts $(P<0.0001)$.

\section{Discussion}

These results demonstrate that antibiotics and current-use pesticides were prevalent in the conventionally produced but not the organically produced milk samples collected from retail sites across the USA. Our findings also demonstrated significantly higher levels of growth hormone in the conventional samples. Pesticide and antibiotic levels detected were within existing federal tolerance limits with some important exceptions. One of the eleven antibiotics tested, amoxicillin, had residues exceeding the limit in one (3\%) of the conventional samples and residues of two sulfonimides prohibited for use in lactating cattle, sulfamethazine and sulfathiazole, were detected in a number of these samples.

While none of the organic milk samples had detectable levels of current-use pesticides, most of the conventional samples did. Not only did chlorpyrifos exceed federal limits in four samples, its residues were present in 59\% of them. Our results contrast with those reported by the FDA in 2015. Although in that study the findings for milk were combined with those for eggs, only $2.6 \%$ of the thirty-nine 'dairy and egg' samples tested had detectables levels of pesticides ${ }^{(45)}$. It is important to note that the levels of detection for the laboratory methods used were not reported in the FDA study, which compromises our ability to draw comparisons. No previous studies documenting pesticide levels relative to limits, or providing a comparison between levels in organic and conventionally produced milk, have been identified.

Although no detectable levels of current-use pesticides were found in any of the organic milk samples, residues of three legacy pesticides were found in nearly all samples, organic and conventional. This included the organochlorines ppDDT, ppDDE (a metabolite and environmental degradate of ppDDT) and hexachlorobenzene, with levels of the latter two significantly higher in conventional compared with organic milk. While the US Department of Agriculture standards for organic feed production prohibit the use of synthetic pesticides on the land for 3 years prior to certification ${ }^{(46)}$, the half-life of some of these pesticides, such as the once commonly used organochlorines, is 15 years $^{(47)}$. This persistence in the soil on which food for organic milk-producing cows is grown could be the mechanism through which they are exposed to these pesticides.

In regard to the testing for antibiotics, our results demonstrating $3 \%$ of samples exceeded tolerance limits for amoxicillin compares with the results of a larger study published by the FDA in 2015 in which < $1 \%$ of the 1918 samples tested exceeded federal limits for the antibiotics tested $^{(23)}$. Amoxicillin levels were not tested and specific levels of the various antibiotics detected were not reported in that study. Amoxicillin is a $\beta$-lactam antimicrobial agent in the family of penicillins, which are known allergens for a large proportion (as high as $10 \%$ ) of the population ${ }^{(19)}$. While the results of the previous FDA study ${ }^{(23)}$ demonstrated that, with a few exceptions, antibiotic residue levels were within federal safety limits, our finding that multiple samples exceeded them suggests that further strengthening of the monitoring system is needed to ensure the continued safety of the milk supply. Our analyses comparing antibiotic levels between organic and conventional milk samples demonstrated significantly lower levels in organic milk, which contrasts with the findings of a 2006 study done by Vicini et al. In that study, no detectable levels of antibiotics were found in either the organic or the conventional milk samples collected from all US states by employees of the Monsanto Corporation $^{(24)}$. The levels of detection for the laboratory analysis methods used in that study were not reported.

As growth hormones are produced naturally by dairy cattle, some level of bGH is to be expected in all milk samples, whether produced organically or using conventional methods. We found that the levels of bGH and IGF-1 in conventional milk were significantly greater than those in the samples produced organically. Median bGH levels were $9.8 \mathrm{ng} / \mathrm{ml}$ in conventional milk and $0.5 \mathrm{ng} / \mathrm{ml}$ in organic milk $(P<0.0001)$. These levels are substantially higher than those reported by Vicini et al. in their 2006 study of retail milk. In that study, geometric mean (SE) bGH levels, adjusted for milk fat percentage and region, were $0.005(0.002) \mathrm{ng} / \mathrm{ml}$ in conventional milk and 0.002 $(0.001) \mathrm{ng} / \mathrm{ml}$ in organic milk $^{(24)}$. When we repeated our analysis to obtain the adjusted geometric mean as was done 
in the earlier study, the results closely approximated those obtained in our primary analysis. The higher recombinant growth hormone levels in conventional $v$. organic samples calls into question the statement in the 2014 WHO review on drug residues that cited similar concentrations of bovine somatotropin (bGH) in the milk of recombinant bovine somatotropin (rbGH)-treated and untreated cattle as evidence in support of the safety of $\mathrm{rbGH}^{(28)}$. Despite the higher levels of recombinant growth hormone by milk type and in the present compared with the previous retail study, it is imporant to note that the recent WHO review concluded that levels hundreds of times higher would be needed for orally consumed bGH to have a biological impact in $\operatorname{man}^{(28)}$.

While the magnitude of the difference was lower, we also found IGF-1 levels to be higher in the conventional $v$. organic milk samples, 3.2 times higher in conventional compared with organic milk, $3.5 v .1 .1 \mathrm{ng} / \mathrm{ml}(P<0.0001)$. Our results are consistent with those reported by Vicini et al. showing significantly higher adjusted least-square mean IGF-1 levels in conventional, $3 \cdot 1 \mathrm{ng} / \mathrm{ml}$, compared with organic milk, $2.7 \mathrm{ng} / \mathrm{ml}(P=0.001)^{(24)}$, as well as with those reported in a $1989^{(48)}$ study conducted by Prosser et al. in which the concentrations of IGF-1 in the milk treated with recombinantly derived bGH increased 3.6 times after $7 \mathrm{~d}$ of treatment, from a mean of $0.44 \mathrm{nmol} / \mathrm{l}$ $(0.18 \mathrm{ng} / \mathrm{ml})$ to $1.6 \mathrm{nmol} / 1(0.64 \mathrm{ng} / \mathrm{ml})^{(49)}$. Despite the observed higher concentrations of IGF-1 in milk produced using conventional $v$. organic methods, a recent WHO review suggests that these higher levels would be expected to have little impact as people naturally produce IGF-1 at much higher levels. Adults produce $10 \mathrm{mg} / \mathrm{d}^{(28)}$ and maintain a mean plasma IGF-1 concentration in the range of $120-460 \mathrm{ng} / \mathrm{ml}^{(48)}$.

\section{Strengths and limitations}

To our knowledge, the present study is the first to compare levels of pesticides in the US milk supply by production method (conventional $v$. organic). It is also the first in a decade to measure antibiotic and hormone levels and compare them by milk production type. Our use of highly sensitive and specific laboratory methods provided valid estimates of the chemicals of interest. In addition, our analysis focused on milk with $2 \%$ milk fat - the type most commonly consumed in the USA - and tested samples collected from retail stores across the country. We were also able to control for seasonal variations in feeding practices by collecting all samples during the same summer month (August) in the same year. Finally, while there were some chemicals where most of the samples had no detectable values (as high as $87 \%$ of the samples), the availability of a single reporting level (or LOD) per chemical allowed us to use suitable non-parametric methods to test differences among groups of interest ${ }^{(43)}$. These ranking methods will not give a false positive as using equal ranks for values censored as $1 / 2 \times$ LOD allowed us to state no more than what is known. For chemicals with $<50 \%$ LOD, using the ranksum test and reporting median/range values (with the $<$ LOD) allowed us to capture the ordering in our data and prevent any loss of information from dichotomizing the data into percentage detected $v$. non-detected.

The study also had important limitations. The laboratory methods used to assess the levels of antibiotics, pesticides and hormones differed from those used in previous studies $^{(22)}$. As a result, comparisons between studies must be made with caution. In addition, the lack of a laboratory method capable of differentiating the synthetic from the naturally occurring growth hormone limited us to an examination of total bGH levels. The difference between levels in conventional and organic milk was used as an estimate of the synthetic rbGH. Also, the LOD for some chemicals, specifically the ionophores, is as high as $10 \mathrm{ng} / \mathrm{ml}$, compared with $1 \mathrm{ng} / \mathrm{ml}$ or lower for others. As a result, it is possible that there are differences in the level of these pesticides between conventional and organic milk that we were unable to detect. While the use of a convenience-based sampling methodology limits our ability to generalize our findings, the fact that milk samples were purchased from local retail stores throughout the country suggests that the results are reflective of milk commonly being consumed. Due to the small number of samples we were unable to examine regional differences that may have provided insight into local factors that influence the use of production-related chemicals. Similarly, we were not able to compare levels by the fat content of the milk samples. Finally, the study design did not allow for an assessment of the health impact of human exposure to the production-related chemicals in milk.

\section{Conclusion}

Residues of current-use pesticides and antibiotics appear to be common in conventional but not organic milk sold through retails stores across the USA, at times exceeding federal tolerance limits. Similarly, growth hormone and IGF-1 levels were several times higher in conventional milk, which suggests that the difference reflects the use of synthetic growth hormones. While further research is needed to understand the lifetime risk, if any, to milk consumers resulting from their exposure to these chemicals, the present study's findings suggest that choosing to consume milk produced organically would minimize exposure and any possible associated risks.

\section{Acknowledgements}

Acknowledgements: The authors would like to thank the following volunteers for their assistance in procuring the milk samples used in this study: Lori Stirn, Star Sloan, 
Shandell Rosa, Andrea Smerud, Miriam Vos, Laura Silva and Amanda Gregory. Financial support: Data collection was supported by the Organic Center (grant number 0000033485). The Organic Center had no role in the design, analysis of samples, or writing of this article. Conflict of interest: J.A.W.'s investment portfolio includes equity in one of the companies whose milk products were randomly selected for use in this study. All other authors have no perceived or potential conflicts of interest to report. Authorship: J.A.W. conceived of and designed the study; the study protocol was drafted by J.A.W. and N.B. with review by D.B.B.; N.B. received the samples and developed the results database; data analysis was done by J.F.; research assistance and guidance on laboratory methods was provided by K.E.; D.B. analysed the samples; the manuscript was drafted by H.B.; all authors reviewed and provided inputs on the draft of the manuscript and approved the final version. Ethics of human subject participation: Not applicable.

\section{References}

1. Maguire JL, Lebovic G, Kandasamy S et al. (2013) The relationship between cow's milk and stores of vitamin $\mathrm{D}$ and iron in early childhood. Pediatrics 131, e144-e151.

2. Dugan CE \& Fernandez ML (2014) Effects of dairy on metabolic syndrome parameters: a review. Yale J Biol Med 87, 135-147.

3. Lee M, Lee H \& Kim J (2018) Dairy food consumption is associated with a lower risk of the metabolic syndrome and its components: a systematic review and meta-analysis. $\mathrm{Br} \mathrm{J}$ Nutr 120, 373-384.

4. Beydoun MA, Fanelli-Kuczmarski MT, Beydoun HA et al. (2018) Dairy product consumption and its association with metabolic disturbance in a prospective study of urban adults. BrJ Nutr 119, 706-719.

5. Thorning TK, Raben A, Tholstrup T et al. (2016) Milk and dairy products: good or bad for human health? An assessment of the totality of scientific evidence. Food Nutr Res 60, 3252732527.

6. US Department of Health and Human Services \& US Department of Agriculture (2015) 2015-2020 Dietary Guidelines for Americans, 8th ed. http://health.gov/ dietaryguidelines/2015/guidelines/ (accessed November 2017).

7. Mesirow MS \& Welsh JA (2014) Changing beverage consumption patterns have resulted in fewer liquid calories in the diets of US children: National Health and Nutrition Examination Survey 2001-2010. J Acad Nutr Diet 115, 559-566.e4.

8. US Department of Agriculture, Economic Research Service (2017) Organic Market Overview. https://www.ers.usda.gov/ topics/natural-resources-environment/organic-agriculture/ organic-market-overview/ (accessed February 2017).

9. Landers TF, Cohen B, Wittum TE et al. (2012) A review of antibiotic use in food animals: perspective, policy, and potential. Public Health Rep 127, 4-22.

10. US Environmental Protection Agency (2018) Why We Use Pesticides. https://www.epa.gov/safepestcontrol/whywe-use-pesticides? (accessed December 2018).

11. Muñoz-Quezada MT, Lucero BA, Barr DB et al. (2013) Neurodevelopmental effects in children associated with exposure to organophosphate pesticides: a systematic review. Neurotoxicology 39, 158-168.

12. Lemarchand C, Tual S, Levêque-Morlais N et al. (2017) Cancer incidence in the AGRICAN cohort study (2005-2011). Cancer Epidemiol 49, 175-185.

13. US Environmental Protection Agency (2017) Setting Tolerances for Pesticide Residues in Foods. https://www.epa.gov/pesticidetolerances/setting-tolerances-pesticide-residues-foods (accessed December 2017).

14. US Environmental Protection Agency (2016) About Pesticide Tolerances. https://www.epa.gov/pesticide-tolerances/aboutpesticide-tolerances (accessed April 2017).

15. Nicolopoulou-Stamati P, Maipas S, Kotampasi C et al. (2016) Chemical pesticides and human health: the urgent need for a new concept in agriculture. Front Public Health 4, $148-148$.

16. Sheldon L, Cohen Hubal E, Tulve N et al. (2002) EPA Children's Pesticide Exposure Measurement Program. Presented at 2002 International State of Science Symposium on Agricultural Exposures and Cancer, Oxford, United Kingdom, November 19-22, 2002. https://cfpub.epa.gov/si/si_public_ record_report.cfm?Lab=NERL\&dirEntryId=62686 (accessed January 2019).

17. Luzardo OP, Almeida-González M, Henríquez-Hernández LA et al. (2012) Polychlorobiphenyls and organochlorine pesticides in conventional and organic brands of milk: occurrence and dietary intake in the population of the Canary Islands (Spain). Chemosphere 88, 307-315.

18. Sawant AA, Sordillo LM \& Jayarao BM (2005) A survey on antibiotic usage in dairy herds in Pennsylvania. J Dairy Sci 88, 2991-2999.

19. Solensky R (2003) Hypersensitivity reactions to beta-lactam antibiotics. Clin Rev Allergy Immunol 24, 201-219.

20. Singer RS, Finch R, Wegener HC et al. (2003) Antibiotic resistance - the interplay between antibiotic use in animals and human beings. Lancet Infect Dis 3, 47-51.

21. US Food and Drug Administration (2018) Code of Federal Regulation Titile 21 (Food and Drugs). https://www. accessdata.fda.gov/scripts/cdrh/cfdocs/cfcfr/CFRSearch.cfm? CFRPart=556\&showFR=1 (accessed November 2018).

22. National Research Council, Committee on Drug Use in Food Animals (1999) 5: Drug residues and microbial contamination in food: monitoring and enforcement. In The Use of Drugs in Food Animals: Benefits and Risks. Washington, DC: National Academies Press; available at https://www. ncbi.nlm.nih.gov/books/NBK232575/

23. US Food and Drug Administration \& US Department of Health and Human Services (2015) Milk Drug Residue Sampling Survey. https://www.fda.gov/downloads/AnimalVeterinary/ ComplianceEnforcement/UCM435759.pdf (accessed January 2016).

24. Vicini J, Etherton T, Kris-Etherton P et al. (2008) Survey of retail milk composition as affected by label claims regarding farm-management practices. J Am Diet Assoc 108, 1198-1203.

25. Etherton TD (1991) Clinical review 21: The efficacy and safety of growth hormone for animal agriculture. J Clin Endocrinol Metab 72, 957A-957C.

26. US Food and Drug Administration (2009) Report on the Food and Drug Administration's Review of the Safety of Recombinant Bovine Somatotropin. https://www.fda.gov/ animalveterinary/safetyhealth/productsafetyinformation/ ucm130321.htm (accessed April 2017).

27. Dohoo IR, DesCôteaux L, Leslie K et al. (2003) A meta-analysis review of the effects of recombinant bovine somatotropin: 2. Effects on animal health, reproductive performance, and culling. Can J Vet Res 67, 252-264.

28. World Health Organization (2014) Evaluation of Certain Veterinary Drug Residues in Food. Seventy-eighth Report of the Joint FAO/WHO Expert Committee on Food Additives. 
WHO Technical Report Series no. 988. https://www.who. int/foodsafety/publications/technical-report-series-988/en/ (accessed March 2017).

29. Shi R, Yu H, McLarty J et al. (2004) IGF-I and breast cancer: a meta-analysis. Int J Cancer 111, 418-423.

30. Rinaldi S, Cleveland R, Norat T et al. (2010) Serum levels of IGF-I, IGFBP-3 and colorectal cancer risk: results from the EPIC cohort, plus a meta-analysis of prospective studies. Int J Cancer 126, 1702-1715.

31. Rowlands MA, Gunnell D, Harris R et al. (2009) Circulating insulin-like growth factor peptides and prostate cancer risk: a systematic review and meta-analysis. Int J Cancer 124, 2416-2429.

32. Ma J, Giovannucci E, Pollak M et al. (2001) Milk intake, circulating levels of insulin-like growth factor-I, and risk of colorectal cancer in men. J Natl Cancer Inst 93, 1330-1336.

33. Malekinejad H \& Rezabakhsh A (2015) Hormones in dairy foods and their impact on public health - a narrative review article. Iran J Public Health 44, 742-758.

34. Mero A, Kahkonen J, Nykanen T et al. (2002) IGF-I, IgA, and IgG responses to bovine colostrum supplementation during training. J Appl Physiol 93, 732-739.

35. Philipps AF, Kling PJ, Grille JG et al. (2002) Intestinal transport of insulin-like growth factor-I (IGF-I) in the suckling rat. J Pediatr Gastroenterol Nutr 35, 539-544.

36. Rich-Edwards JW, Ganmaa D, Pollak MN et al. (2007) Milk consumption and the prepubertal somatotropic axis. Nutr J 6, 28.

37. Seaman WJ, Nappier JL, Olsen RF et al. (1988) The lack of a growth-promoting effect of orally administered bovine somatotropin in the rat body-weight-gain bioassay. Fundam Appl Toxicol 10, 287-294.

38. Hamner CH, Perrine GC, Gupta MP et al. (2017) Food consumption patterns among US children from birth to 23 months of age, 2009-2014. Nutrients 9, E942.

39. Sebastian RS, Goldman JD, Enns CW et al. (2010) Fluid Milk Consumption in the United States: What We Eat In America, NHANES 2005-2006. Food Surveys Research Group Dietary Data Brief no. 3, September 2010. https://www.ars.usda.gov/ ARSUserFiles/80400530/pdf/DBrief/3_milk_consumption_ 0506.pdf (accessed August 2017).
40. Organic Valley (2015) Local, Organic, and Farmer-Owned. https://www.organicvalley.coop/ (accessed March 2015).

41. Martins JG, Amaya Chavez A, Waliszewski SM et al. (2013) Extraction and clean-up methods for organochlorine pesticides determination in milk. Chemosphere $\mathbf{9 2}$, 233-246.

42. Kay RG, Barton C, Velloso CP et al. (2009) High-throughput ultra-high-performance liquid chromatography/tandem mass spectrometry quantitation of insulin-like growth factor-I and leucine-rich $\alpha$-2-glycoprotein in serum as biomarkers of recombinant human growth hormone administration. Rapid Commun Mass Spectrom 23, 3173-3182.

43. Helsel DR (2012) Statistics for Censored Environmental Data Using Minitab and R. Hoboken, NJ: John Wiley and Sons, Inc.

44. National Pesticide Information Center (2018) Legacy Pesticides. http://npic.orst.edu/ingred/legacy.html (accessed January 2019).

45. Bates LA, Councell T, Kelly MK et al. (2017) Pesticide Residue Monitoring Program Fiscal Year 2015 Pesticide Report: US Food and Drug Administration. https://www. fda.gov/downloads/Food/FoodborneIllnessContaminants/ Pesticides/UCM582721.pdf (accessed December 2017).

46. US Government Publishing Office (2016) Electronic Code of Federal Regulations, National Organic Program. https:// www.ecfr.gov/cgi-bin/text-idx?SID=6efb7951e5f9c6c910dc 016d40e65f9a \&mc=true \&node=se7.3.205_1202\&rgn=div8 (accessed August 2018).

47. Jayaraj R, Megha P \& Sreedev P (2016) Organochlorine pesticides, their toxic effects on living organisms and their fate in the environment. Interdiscip Toxicol 9, 90-100.

48. World Health Organization (1999) Evaluation of Certain Veterinary Drug Residues in Food. Fiftieth Report of the Joint FAO/WHO Expert Committee on Food Additives. WHO Technical Report Series no. 888. https://apps.who. int/iris/bitstream/handle/10665/42182/WHO_TRS_888.pdf? sequence=1\&isAllowed=y (accessed February 2019).

49. Prosser CG, Fleet IR \& Corps AN (2009) Increased secretion of insulin-like growth factor I into milk of cows treated with recombinantly derived bovine growth hormone. J Dairy Res 56, $17-26$. 